\title{
Spatial Propagation of Macroeconomic Shocks in Europe*
}

\author{
Hans Dewachter, Romain Houssa $a^{\ddagger}$ and Priscilla Toffano ${ }^{\S}$
}

April 2010

\begin{abstract}
This paper develops a Spatial Vector Auto-Regressive (SpVAR) model that takes into account both the time and the spatial dimensions of economic shocks. We apply this framework to analyze the propagation through space and time of macroeconomic (inflation, output gap and interest rate) shocks in Europe. The empirical analysis identifies an economically and statistically significant spatial component in the transmission of macroeconomic shocks in Europe.
\end{abstract}

JEL classifications: E3, E43, E52, C51, C33

Keywords: Macroeconomics, Spatial Models, VAR

${ }^{*}$ We acknowledge financial support from FWO grant $\mathrm{N}^{\circ}$ G.0626.07.

${ }^{\dagger} \mathrm{CES}$, University of Leuven, RSM Rotterdam and CESIFO.

${ }^{\ddagger}$ CRED, CEREFIM-University of Namur, CES, University of Leuven.

$\S$ CES, University of Leuven. 


\section{Introduction}

Over the last decades, spatial econometrics has emerged as a distinct field in econometrics. Contributions in this field include Anselin (2001), Cliff \& Ord (1981), Elhorst (2003), Kapoor et al. (2007), Lee (2004), Lee \& Yu (2010), and LeSage \& R. Kelley (2004) (see Anselin (2010) and Lee \& Yu (2009) for a recent review of the literature), while textbook treatments of spatial econometrics can be found in Anselin (1988) and LeSage \& Pace (2009). The development and success of (dynamic) spatial econometrics primarily stems from the need to appropriately account for economic dynamics with a pronounced spatial dependence. Examples of data generating this kind of dynamics comprise housing prices, economic activity, financial indicators and census data in general. The presence of such a spatial dependence necessitates the modeling of the joint dynamics. However, standard time series techniques, i.e. unrestricted VAR models, run quickly into problems associated with the so-called curse of dimensionality. Spatial econometrics provides tools to overcome the curse of dimensionality by introducing, next to temporal lags, the concept of spatial lags, which allows to concisely capture spatial dependence. ${ }^{1}$

In this paper, we develop a Spatial Vector Auto-Regressive ( $S p V A R)$ model to account for both the time and spatial dimensions of standard macroeconomic shocks. In particular, we model the interdependence across three key macroeconomic indicators for a set of European countries. Specifically, we focus on inflation, output and interest rate dynamics across eleven European countries. For these purposes, Spatial Auto-Regressive models (SAR) including both spatial and temporal lags (see Anselin (1988), Anselin et al. (2008), Cliff \& Ord (1981), Lee \& Yu (2009) and LeSage \& Pace (2009)) are estimated for, respectively, inflation, output and interest rate dynamics. Subsequently, we aggregate the variable-specific SAR models into a $S p V A R$ model by taking into account the dynamic interactions between the respective economic variables. The model is estimated using standard ML techniques and the spatial propagation of shocks is analyzed by means of impulse response functions and variance decompositions.

The $S p V A R$ model used in this paper is a restricted version of Global $V A R(G V A R)$ models introduced in the literature (see for instance M.H. et al. (2004), di Mauro et al. (2007)). In particular, the $S p V A R$ and the $G V A R$ specifications model spatial dependence

\footnotetext{
${ }^{1}$ Note that regional interdependency issues can also be addressed in factor models. Applications include Kose et al. (2003), Forni \& Reichlin (1998) and Houssa (2008).
} 
by introducing an aggregated spatial variable, summarizing the economic conditions in the neighboring countries. $G V A R$ and $S p V A R$ models, thus, replace observations of foreign variables by their weighted average, where the weights represent entries of the well-known spatial weighting matrix (see Anselin (1988), Cliff \& Ord (1981), and LeSage \& Pace (2009)). In most of the applications, geographical distance between two units has been used to define the spatial weighting matrix. Recently, however, it has been argued that also economic distance can be used for this purpose (see for instance Beck et al. (2006)). We take into account three different measures for the weighting matrix. First, we consider the binary matrix, originally proposed by Moran (1948), which attributes a value of 1 to spatial units with a border of non zero length in common and a value of 0 otherwise. Second, we use a spatial weighting matrix based on the geographical distance between countries. Third, we define the spatial weighting matrix using information on trade linkages among the economies. The results are qualitatively similar across the three weighting matrices. Our preference for $S p V A R$ model over the $G V A R$ specification is due to its parsimony. In particular, instead of assuming country-specific spatial lag parameters, as in the $G V A R$ specification, we impose a single spatial lag structure. The latter assumption allows to better identify the spatial lag parameter through panel estimation techniques.

Overall, we find significant spatial dependence across European countries leading to significant and persistent spatial dispersion of local shocks. Specially, our $S p V A R$ model identifies a larger impact of macroeconomic shocks on nearby European countries than on more remote ones. $S p V A R$ models have been applied to housing price shocks in Beenstock \& Felsenstein (2007) and Brady (2009), and to demographic shocks in Azomahou et al. (2009).

The remainder of this paper is organized as follows. Section 2 introduces the theoretical $S p V A R$ framework and specializes this general framework to obtain a parsimonious model for macroeconomic dynamics. Section 3 discusses the empirical results. We focus first

on assessing the statistical significance of spatial spillovers. Subsequently, we illustrate the impact of spatial dependence by discussing the spatial propagation of macroeconomic shocks. Section 4 concludes.

\section{Spatial Vector Auto-Regression Model}

In this section, we first set out the econometric framework used to summarize the dynamic interactions among economies. Subsequently, we specialize this framework to model macroeconomic space and time interactions for a set of European countries. Finally, we discuss the identification of structural shocks. 


\section{$2.1 \quad$ Econometric model}

Denote by $y_{i, t}$ a zero mean ${ }^{2} l$-dimensional state vector summarizing the state of the economy for country $i, i=1, \ldots, n$, at time $t, t=1, \ldots, T$. We assume that:

$$
y_{i, t}=\Phi_{i} y_{i, t-1}+\rho y_{i, t}^{*}+\varepsilon_{i, t},
$$

where $y_{i, t}=\left(y_{1, i, t}, y_{2, i, t}, \cdots, y_{l, i, t}\right)^{\prime}$ includes $l$ economic indicators for country $i$; $\Phi_{i}$ is a $l \times l$ feedback matrix capturing the temporal effects among the $l$ economic indicators in country $i ; \varepsilon_{i, t}=\left(\varepsilon_{1, i, t}, \varepsilon_{2, i, t}, \cdots, \varepsilon_{l, i, t}\right)^{\prime}$ represents a $l \times 1$ vector of shocks that are assumed to be $i . i . d$. normally distributed as $\varepsilon_{i, t} \sim N\left(0, \Sigma_{i}\right)$. The spatial variable, $y_{i, t}^{*}=\left(y_{1, i, t}^{*}, \cdots, y_{l, i, t}^{*}\right)^{\prime}$, is a $l \times 1$ vector containing suitably transformed foreign state variables, relevant for country $i$. In particular, $y_{i, t}^{*}$ is a weighted average of economic conditions in each of the $n$ countries, i.e. $y_{i, t}^{*}=w_{i}\left(y_{1, t}, y_{2, t}, \cdots, y_{n, t}\right)^{\prime}$, where $w_{i}$ represents the $1 \times n$ vector containing the spatial weights of country $i, i=1, \ldots, n$, with the $i t h$ element of $w_{i}$ set to zero. The $n \times n$ spatial weighting matrix $W$, then, stacks weight vectors for all countries: $W=\left(w_{1}^{\prime}, \ldots, w_{n}^{\prime}\right)^{\prime}$. We measure the spatial dependence for each of the $l$ economic indicators by the parameters of the $l \times l$ diagonal matrix containing the spatial lags coefficients, $\rho:^{3}$

$$
\rho=\left[\begin{array}{llll}
\rho_{1} & 0 & \ldots & 0 \\
0 & \rho_{2} & & 0 \\
\ldots & \ldots & \ddots & \ldots \\
0 & \ldots & & \rho_{l}
\end{array}\right] .
$$

The $S p V A R$ model defined in (1) belongs to the class of spatial dynamic data panel models (see, for example, Anselin (2001), Anselin et al. (2008), Elhorst (2005), and Lee \& $\mathrm{Yu}(2009)) .{ }^{4}$ This class of models embeds two specific and well-known subclasses of models. First, the standard (country-by-country) Vector Auto-Regression (VAR) model introduced by Sims (1980) is obtained if spatial lags are irrelevant (i.e. $\rho=\mathbf{0}$ ). Second, standard (crosssectional) spatial models can be obtained by setting the temporal lag coefficients equal to 0 (i.e. $\left.\Phi_{i}=\mathbf{0}\right)$. Purely cross-sectional and static panel SAR models have been studied in, for instance, Anselin (1988), Cliff \& Ord (1973), Elhorst (2003) and Kapoor et al. (2007).

The $S p V A R$ model implies a standard reduced form VAR representation in the extended

\footnotetext{
${ }^{2}$ Demeaned series follow automatically after removing the country- and series-specific fixed effects.

${ }^{3}$ This amounts to say that $\rho$ measures the average impact of neighboring countries on the respective macroeconomic variables of the country itself.

${ }^{4}$ Similar models have been recently analyzed in the literature (see, for example, Azomahou et al. (2009), Beenstock \& Felsenstein (2007) and Brady (2009)).
} 
state space. Specifically, we construct the extended state space vector, $X_{t}=\left(y_{1, t}^{\prime}, y_{2, t}^{\prime}, \cdots, y_{n, t}^{\prime}\right)^{\prime}$, and stack consecutively equation (1) over the $n$ countries to obtain the $S p V A R$ representation in the extended state space:

$$
X_{t}=\Upsilon \widetilde{W} X_{t}+\Phi X_{t-1}+\varepsilon_{t}
$$

where $\varepsilon_{t}=\left(\varepsilon_{1, t}^{\prime}, \varepsilon_{2, t}^{\prime}, \cdots, \varepsilon_{n, t}^{\prime}\right)^{\prime}$ is a $n l \times 1$ vector of residuals ; $\Upsilon=I_{n} \otimes \rho ; \widetilde{W}=W \otimes I_{l}$; and $\Phi$ is a $n l \times n l$ autoregressive matrix of the extended system represented by:

$$
\Phi=\left[\begin{array}{cccc}
\Phi_{1} & 0 & \cdots & 0 \\
0 & \Phi_{2} & \ddots & \vdots \\
\vdots & \ddots & \ddots & 0 \\
0 & \cdots & 0 & \Phi_{n}
\end{array}\right]
$$

Rearranging, equation (2) yields the reduced form of the global system:

$$
X_{t}=A X_{t-1}+\epsilon_{t}
$$

where $A=(I-\Upsilon \widetilde{W})^{-1} \Phi$ and $\epsilon_{t}=(I-\Upsilon \widetilde{W})^{-1} \varepsilon_{t}$. Equation (3) establishes the $\operatorname{VAR}(1)$ representation of the macroeconomic dynamics. Note, however, that the $S p V A R$ model uses fewer degrees of freedom in identifying these dynamics than a standard VAR model. In particular, by using the idea of spatial lags, the $S p V A R$ model requires fewer parameters to be estimated. In fact, instead of estimating $(n l)^{2}+n l(n l+1) / 2$ parameters as in a standard VAR, we estimate $n l^{2}+l+n l(n l+1) / 2$ parameters, yielding $\left(n^{2}-n\right) l^{2}-l$ additional degrees of freedom. It is easily seen that the increase in the degrees of freedom can be quite sizeable in case $n$ is large. ${ }^{5}$

\subsection{Implementation}

We employ our $S p V A R$ model to analyze the propagation of macroeconomic innovations within and across a set of European countries. In particular, we assess the dynamics of three macroeconomic indicators: inflation $\left(\pi_{t}\right)$, the business cycle measured by the output gap $\left(g_{t}\right)$, and monetary policy measured by the short term interest rate $\left(r_{t}\right)$. The country-specific state vector is thus given by $y_{i, t}=\left(\pi_{i, t}, g_{i, t}, r_{i, t}\right)^{\prime}$. In this setting, we allow for three spatial

\footnotetext{
${ }^{5}$ In the empirical part of the paper we estimate a three equation model $(l=3)$ for eleven countries. Estimating an unrestricted $\operatorname{VAR}(1)$ implies estimating 1650 parameters. The $S p V A R$ in contrast reduces this number to 660. Also, one could additionally assume independence among local shocks, which reduces further the number of parameters to 132 .
} 
lag parameters, $\rho_{\pi}, \rho_{g}$ and $\rho_{r}$, related to $\pi_{t}, g_{t}$, and $r_{t}$, respectively. Moreover, we estimate country-specific temporal lag coefficients, $\phi_{i, k, m}, k, m=\{\pi, g, r\}$. Specifically, we consider the following system of three spatial dynamic panel models analogous to (1):

$$
\left\{\begin{aligned}
& \pi_{i, t}=\rho_{\pi} \sum_{j=1}^{n} w_{i j} \pi_{j, t}+\phi_{i, \pi \pi} \pi_{i, t-1}+\phi_{i, \pi g} g_{i, t-1}+\phi_{i, \pi r} r_{i, t-1}+\varepsilon_{i, \pi, t}, \\
& g_{i, t}=\rho_{g} \sum_{j=1}^{n} w_{i j} g_{j, t}+\phi_{i, g \pi} \pi_{i, t-1}+\phi_{i, g g} g_{i, t-1}+\phi_{i, g r} r_{i, t-1}+\varepsilon_{i, g, t} \\
& r_{i, t}=\rho_{r} \sum_{j=1}^{n} w_{i j} r_{j, t}+\phi_{i, r \pi} \pi_{i, t-1}+\phi_{i, r g} g_{i, t-1}+\phi_{i, r r} r_{i, t-1}+\varepsilon_{i, r, t}, \\
& \text { for } i=1, . ., n, t=1, \ldots, T
\end{aligned}\right.
$$

where the first term on the RHS captures the respective spatial lag effects while the remaining terms model the temporal lag dependencies. We estimate the system (4) equation by equation. Note that due to the presence of the spatial lag structure, estimating the system (4) by OLS is in general problematic because the inclusion of spatial interdependencies compromises the unbiasedness and consistency of the LS estimator (see for example Anselin (1988), LeSage (1998) and LeSage \& Pace (2009)). ${ }^{6}$ For these reasons, we use maximum likelihood (ML) estimators along the lines proposed by Anselin (1988). Lee (2004) and Lee \& Yu (2009) show consistency of the ML estimator. It is also important to note that the ML estimation method for our model (in the presence of fixed effects) is biased because the inclusion of lagged dependent variables creates an endogeneity problem (for a discussion, see for example Kukenova \& Monteiro (2008) and Lee \& Yu (2009)). Moreover, our modeling approach, allowing for country-specific temporal lag coefficients, increases the number of parameters and gives rise to the so-called incidental parameter problem (see, for instance, Neyman \& Scott (1948) and Lancaster (2000)). Nonetheless, the impact of these two problems should be small in our case for two reasons. First, we assume, as it is standard in the VAR literature, that observations of the (lagged) economic indicators in $y_{i, t}=\left(\pi_{i, t-1}, g_{i, t-1}, r_{i, t-1}\right)^{\prime}$ are independent from current error terms, $\varepsilon_{i, \pi, t}, \varepsilon_{i, g, t}$ and $\varepsilon_{i, r, t}$, respectively. As shown by Nickell (1981), the endogeneity bias in the case of fixed effects is of the order $1 / T$. Second, for fixed $n$, the bias related to the incidental parameter problem (arising from the country-specific temporal lag structure) tends to zero as $T \rightarrow \infty$. Our empirical analysis meets these requirements as we analyze data on eleven countries $(n=11)$ covering quarterly observations from $1981: 1$ till $2008: 4(T=100)$.

\footnotetext{
${ }^{6}$ In fact, the Gauss-Markov assumption that explanatory variables are independent from disturbance is violated.
} 


\subsection{Identification of Macroeconomic Shocks}

Our shock identification strategy is based on two sets of identification restrictions. First, at a country level, we apply a standard Cholesky factorization on the variance-covariance matrix, $\Sigma_{i}$. This identification technique has been widely used for the identification of monetary policy shocks (see for example Christiano et al. (1999)). In particular, given the ordering of variables in $y_{i, t}=\left(\pi_{i, t}, g_{i, t}, r_{i, t}\right)^{\prime}$, we assume that output and inflation do not respond contemporaneously to disturbances in the short term interest rate. Moreover, we postulate that output shocks do not impact contemporaneously on inflation within a country. Second, we assume that big countries do not respond contemporaneously to innovations in small countries. In analogy with the first type of identification scheme, we order the economic indicators such that those of the big countries come first and the ones of the small last. Combining the two sets of identification restrictions amounts to order first the eleven series of inflation followed by the eleven series of output gap and, finally, the eleven series of interest rate. The series of every macroeconomic variable are ordered in relation to the dimension of the countries. ${ }^{7}$

These identification restrictions require a re-ordering of the system equations (and shocks) in (2). Recall that the reduced form of the extended system in equation (3) orders equations and shocks on a country-by-country basis while the identification restrictions require a variable-by-variable ordering. This required re-ordering is obtained through a transformation matrix $R$. In particular, the $R$ matrix re-orders equations such that inflation equations come first, followed by output gap equations and interest rate equations. As previously mentioned, within each category, countries are ranked by size.

To be more specific, let us define $\eta_{t}=R \epsilon_{t}$ as the new vector of residuals, ordered according to the identification scheme discussed above. This reordering is obtained by rearranging (using $R$ ) the original shocks, $\epsilon_{t}$, in the reduced form model (see equation (3)). Rewrite $\eta_{t}$ as:

$$
\eta_{t}=Q v_{t}
$$

where $Q$ is the lower triangular Cholesky factor of the variance-covariance matrix of $\eta_{t}$ while $v_{t}$ represents the implied $n l \times 1$ vector of univariate structural macroeconomic shocks. Having obtained this identification, we perform the necessary matrix rotations to recast the structural shocks to the original ordering of the extended $V A R$, where variables are ordered per country. To do so, we first get to $\epsilon_{t}=R^{-1} \eta_{t}$, use equation (5) and rearrange to obtain:

\footnotetext{
${ }^{7}$ The actual ranking of countries is discussed in the data section.
} 


$$
\epsilon_{t}=R^{-1} Q R u_{t}
$$

where $u_{t}=R^{-1} v_{t}$ represents the structural shocks ordered on a country-by-country basis, as in $\epsilon_{t}$. Finally, substituting $\epsilon_{t}=R^{-1} Q R u_{t}$ in equation (3) and rearranging gives the impulse response functions (IRFs):

$$
X_{t}=(I-A L)^{-1} R^{-1} Q R u_{t}
$$

where $L$ is the time lag operator.

\section{Empirical Analysis}

\subsection{Data}

The empirical analysis is carried out on a sample of eleven European countries - UK, Germany, France, Italy, Spain, Switzerland, the Netherlands, Belgium, Portugal, Austria and Denmark - over the period 1981:Q1 till 2008:Q4. For each country, three types of macroeconomic series are considered: inflation, output gap and the short term interest rate. Inflation is computed as the four-quarter log difference of the CPI index and is expressed in annual terms. The output gap is the difference between actual and potential output, with potential output obtained by applying the Hodrick-Prescott filter ${ }^{8}$ on the seasonally adjusted GDP index. The short-term interest rate is represented by short-term repo rate for Germany, Italy, Spain, Portugal, the Netherlands, Belgium and Austria, by the central bank discount rate in UK and Denmark, by the three-month interbank rate in France and Switzerland. All series are demeaned and expressed in percentage. The data are obtained from the $O E C D$ and $I M F$ databases.

As stressed by Anselin (1988), the determination of the proper spatial weights may impact on the estimation. Therefore, we use three different empirical specifications for the spatial weighting matrix which can be summarized as follows. First, we consider the binary matrix, originally proposed by Moran (1948), which attributes a value of 1 to spatial units with a common border of non zero length and a value of 0 otherwise. Second, we use a spatial weighting matrix based on the geographical distance between countries. In particular, we use the latitude and longitude coordinates of capital cities of countries to construct weights such that two points are considered as neighbors if their vertices belong

\footnotetext{
${ }^{8}$ It is customary to set $\lambda$ to 1,600 for quarterly data.
} 
to the same Delaunay triangle ${ }^{9}$. Finally, we use economic distance as a third option to specify the weighting matrix. Economic distance is defined using information on trade linkages among the eleven countries. The motivation for considering trade linkages is based on several empirical findings indicating that countries which trade more are typically closer connected economically, e.g. have more correlated business cycles (see, for instance, Frankel \& Rose (1998)). For any pair of two countries, $i$ and $j, i \neq j$, we define the bilateral weights as $w_{i j}=\left(E X P O R T_{i j}+I M P O R T_{j i}\right) / 2$, where $E X P O R T_{i j}$ is the value of export of goods and services from $i$ to $j$ and $I M P O R T_{j i}$ represents the import counterpart into country $j$ from country $i .{ }^{10}$ In the estimation process, we consider a standardized version of the weighting matrices defined above. We obtain this by normalizing the weights such that each of the rows of the spatial weighting matrix sums up to 1 . This normalization offers an interpretation of the weight vector in relative terms and additionally presents the advantage of enhancing dynamic stability (see Robinson (2008)).

\subsection{Empirical Results}

As a first step, we perform a preliminary test on spatial dependence of macroeconomic conditions in Europe. For this purpose, we employ the popular spatial test developed by Moran (1950). Under the null hypothesis of no spatial correlation, it has been shown that the asymptotic distribution of a normalization of the Moran test statistic is standard normal (see, for example, Cliff \& Ord (1972), Cliff \& Ord (1973), and Cliff \& Ord (1981)).

\section{Insert Table 1}

Table 1 lists the normalized Moran statistics for the alternative spatial weighting matrices defined above. The Moran statistics reject the null-hypothesis of no spatial correlation for all standard significance levels, irrespective of the weighting matrix. This result suggests that the omission of a spatial component in regression analysis on macroeconomic developments in Europe would lead to biased estimation results.

\subsubsection{Dynamic Spatial Panel Models for Macroeconomics in Europe}

We now turn to the estimation results of the spatial lag coefficients in equation (4). Table 2 displays estimates for the spatial lag coefficients in the three equations and across the three weighting matrices.

\footnotetext{
${ }^{9}$ For details on this see LeSage (1998) and LeSage \& Pace (2009).

${ }^{10}$ We consider this average to account for asymmetries in the reporting of export and import data.
} 


\section{Insert Table 2}

The results reported in Table 2 confirm our earlier findings based on the Moran statistics. In particular, Table 2 shows that inflation, output gap and interest rate developments in Europe display a clear spatial dependence. The estimated spatial parameters are statistically different from zero at standard significance levels. This finding is robust against the alternative choices of the weighting matrix. The weighting matrix based on geographical distance provides the highest log-likelihood to the data for two out of the three series (i.e. for the output gap and the interest rate series). For this reason, we concentrate on results based on this matrix for the remainder of the paper. ${ }^{11}$ Tables 3 to 5 present the estimation results for equations (4) to (6) using the weighting matrix on geographical distance. Figures 1 to 3 illustrate the fit of the model for, respectively, inflation, output gap and interest rate.

\section{Insert Tables 3 to 5 and Figures 1 to 3}

The fact that the temporal lag parameters and the spatial lag coefficients are jointly statistically significant suggests that both the time and the spatial dimensions are important to explain the dynamics of macroeconomics data in Europe. Information on country-specific macroeconomic conditions is, therefore, not sufficient to describe or forecast future economic states. In this respect, economic conditions in neighboring countries provide valuable and incremental information in forecasting. Comparing the spatial lag estimates across series reveals that the output gap displays the highest spatial dependence, as measured by the spatial lag parameter, $\rho$. This result suggests that, ceteris paribus, business cycle fluctuations in European countries are even more interconnected than developments in inflation and interest rates. Furthermore, we observe a strong and statistically significant temporal lag coefficient for all series in each of the countries, indicating substantial persistence in the dynamics of the macroeconomic state. Although all parameters indicate substantial persistence, we find smaller persistence (temporal lags) in the output gap series than in either inflation or interest rate dynamics. This feature, obviously, has implications for the transmission of shocks.

\subsubsection{Spatial Propagation of Shocks}

In the $S p V A R$ model, IRFs describe the response of the system to a shock in one variable and provide a summary of the interdependencies over time and across countries. As implied

\footnotetext{
${ }^{11}$ Note, however, that in general the findings of this paper are qualitatively similar across the three weighting matrices. Results based on the other two weighting matrices are available upon request.
} 
by equation (3), our $S p V A R$ model allows for two channels of interactions among countries. First, the model accounts for contemporaneous spatial dependence (impact) of shocks in country $i$ on the shocks of country $j$, measured through the impact matrix $Q$. Second, our framework takes into account the delayed dependence (i.e. feedback) of the economic state in country $i$ on the economic state in contiguous countries, captured by the feedback matrix $A$ (see equations (3) and (7)).

The framework involves 33 sets of IRFs (3 shocks for each of the eleven European countries). Instead of presenting all the results, we concentrate on the spatial propagation of macroeconomic shocks originating from Germany, the largest economy of the euro area. ${ }^{12}$ In particular, we consider IRFs of inflation, output gap and interest rates in each of the eleven countries to a positive shock to, respectively, inflation, output, and interest rates in Germany. Figures 4 to 6 report the estimated IRFs together with the 68 and 90 percent confidence intervals, obtained with the bootstrap method. We then translate these IRFs on a geographical map to more intuitively represent the propagation mechanism. Figures 7 to 9 show maps with point estimates of IRFs at horizons 0, 1, 2, 4, 8 and 100 quarters. The unit of the IRFs is the standard deviation of the respective shocks in Germany.

\section{Insert Figures 4 to 9}

As indicated by the IRFs, the effects of German macroeconomic shocks on other European countries are positive and statistically significant in most cases. Comparing the impact of the respective shocks on the different countries clearly illustrates the spatial dimension of shock propagation. Typically, the impact of German shocks is larger on nearby countries than on more remote ones. For instance, the impact of German inflation shocks tends to be larger in France, Italy and Austria than in the UK, Spain or Portugal. Also, and especially for inflation dynamics, there seems to be evidence of a significant space and time interactions. More remote countries show delayed responses to the German shocks with the maximal impact arriving later than in the more nearby countries (e.g. Portugal). Finally, note that we observe a smaller spatial impact on output gap shocks.

\section{Insert Tables 6 to 8}

A final characterization of the $S p V A R$ model is presented in Tables 6 to 8, containing the variance decomposition of inflation, output gap and interest rates at a five year forecasting horizon. For presentation purposes, we aggregated shocks per country. The entries in the

\footnotetext{
${ }^{12}$ The results on shocks related to other countries are available upon request.
} 
tables, thus, present the fraction of total variance of, respectively, inflation, output gap and interest rate in a specific country explained by shocks originating from each of the countries. This aggregation allows us to focus on the spatial impact of shocks. The results suggest significant spatial spillovers within Europe. First, for big countries, we find that more than 40 percent of the variation in macroeconomic conditions can be explained by 'foreign' shocks. For smaller countries, the percentage of variation explained by foreign shocks even increases to levels over 50 percent. Second, there is an overall relation between nearness and impact. Nearby countries' shocks tend to have more impact than countries farther away. For instance, the German economy seems to be affected significantly by shocks originating in Italy, France, Switzerland, the UK and the Netherlands, while shocks to Spain seem to be originating to a large extent from France. Similar findings apply to smaller countries: e.g. Austrian economic dynamics are significantly affected by shocks originating from Germany, France, Switzerland and the Netherlands. These results confirm the economic relevance of spatial spillover.

\section{Conclusion}

In this paper, we set out a dynamic spatial panel model to account for the dynamics of inflation, output gap and interest rate in eleven European countries for the period 19812008. We are able to jointly specify the temporal dimension, typical of $V A R$ models, and the spatial dimension, typical of cross-section models, in order to describe the interactions among variables of different countries.

We model inflation, output gap and interest rate through SAR processes extended to panel data models and define the relations among neighboring countries through three types of spatial weighting matrices. We then consider the associated $S p V A R$. The results show that the macroeconomic variables of the different countries under analysis are significantly interrelated and that a shock taking place in one country affects its neighbors. In particular, estimation results suggest a large and significant spatial component in the business cycle dynamics, as measured by the output gap. The spatial interdependence is furthermore illustrated by IRFs tracking the spatial propagation of German macroeconomic shocks. We find that these shocks have a significant impact on nearby countries and subsequently, with a time lag, spread out across Europe. 


\section{References}

Anselin, L. (1988), Spatial Econometrics: Methods and Models, Kluwer Academic Publishers.

Anselin, L. (2001), A companion to theoretical econometrics, Basil Blackwell, chapter Spatial Econometrics, pp. 310-330.

Anselin, L. (2010), 'Thirty years of spatial econometrics', Papers in Regional Science Vol. $\mathbf{8 9}(1), 3-25$.

Anselin, L., Le Gallo, J. \& Jayet, H. (2008), Spatial panel econometrics, in L. Matyas \& P. Sevestre, eds, 'The Econometrics of Panel Data, Fundamentals and Recent Developments in Theory and Practice', Dordrecht, Kluwer, pp. 627-662.

Azomahou, T., Diebolt, C. \& Mishra, T. (2009), 'Spatial persistence of demographic shocks and economic growth', Journal of Macroeconomics 31(1), 98-127.

Beck, N., Gleditsch, K. S. \& Beardsley, K. (2006), 'Space is more than geography: Using spatial econometrics in the study of political economy', International Studies Quarterly 50(1), 27-44.

Beenstock, M. \& Felsenstein, D. (2007), 'Spatial vector autoregressions', Spatial Economic Analysis 2(2), 167-196.

Brady, R. R. (2009), 'Measuring the diffusion of housing prices across space and over time', Journal of Applied Econometrics .

Christiano, L. J., Eichenbaum, M. \& Evans, C. L. (1999), Monetary policy shocks: What have we learned and to what end?, in J. B. Taylor \& M. Woodford, eds, 'Handbook of Macroeconomics', Vol. 1, Elsevier Science, North Holland, pp. 65-148.

Cliff, A. D. \& Ord, J. K. (1972), 'Testing for spatial autocorrelation among regression residuals', Geographic Analysis 4, 267-84.

Cliff, A. D. \& Ord, J. K. (1973), Spatial Autocorrelation, Pion.

Cliff, A. D. \& Ord, J. K. (1981), Spatial processes: models and applications, Pion.

di Mauro, F., Smith, L. V., Dees, S. \& Pesaran, M. H. (2007), 'Exploring the international linkages of the euro area: a global var analysis', Journal of Applied Econometrics 22(1), 138. 
Elhorst, J. P. (2003), 'Specification and estimation of spatial panel data models', International Regional Science Review 26, 244-268.

Elhorst, P. J. (2005), 'Unconditional maximum likelihood estimation of linear and log-linear dynamic models for spatial panels', Geographical Analysis 37(1), 85 - 106.

Forni, M. \& Reichlin, L. (1998), 'Let's get real: A factor analytical approach to disaggregated business cycle dynamics', Review of Economic Studies 65(3), 453-73.

Frankel, J. A. \& Rose, A. K. (1998), 'The endogeneity of the optimum currency area criteria', Economic Journal 108(449), 1009-25.

Houssa, R. (2008), Sources of Fluctuations: World, Regional, and National Factors, In Macroeconomic Fluctuations in Developing Countries, PhD thesis, KULeuven.

Kapoor, M., Kelejian, H. H. \& Prucha, I. R. (2007), 'Panel data models with spatially correlated error components', Journal of Econometrics 140(1), 97-130.

Kose, A. M., Otrok, C. \& Whiteman, C. (2003), 'International business cycles: World, region, and country-specific factors', American Economic Review 93(4), 1216-1239.

Kukenova, M. \& Monteiro, J.-A. (2008), Spatial dynamic panel model and system gmm: A monte carlo investigation. IRENE Working Papers with number 09-01.

Lancaster, T. (2000), 'The incidental parameter problem since 1948', Journal of Econometrics 95(2), 391-413.

Lee, L.-F. (2004), 'Asymptotic distributions of quasi-maximum likelihood estimators for spatial autoregressive models', Econometrica 72(6), 1899-1925.

Lee, L.-f. \& Yu, J. (2009), 'Some recent developments in spatial panel data models', Regional Science and Urban Economics, Forthcomings .

Lee, L.-f. \& Yu, J. (2010), 'Estimation of spatial autoregressive panel data models with fixed effects', Journal of Econometrics 154(2), 165-185.

LeSage, J. P. (1998), 'Econometrics: Matlab toolbox of econometrics functions', Statistical Software Components, Boston College Department of Economics.

LeSage, J. P. \& Pace, R. K. (2009), Introduction to Spatial Econometrics, Taylor \& Francis Group, CRC Press,. 
LeSage, J. P. \& R. Kelley, P. (2004), Advances in Econometrics, Volume 18: Spatial and Spatiotemporal Econometrics., Elsevier Science.

M.H., P., T., S. \& S.M., W. (2004), 'Modeling regional interdependencies using a global errorcorrecting macroeconometric model', Journal of Business \& Economic Statistics 22, 129162.

Moran, P. A. P. (1948), 'The interpretation of statistical maps', Journal of the Royal Statistical Society B 10, 243-51.

Moran, P. A. P. (1950), 'Notes on continuous stochastic phenomena', Biometrika 37, 17-33.

Neyman, J. \& Scott, E. L. (1948), 'Consistent estimates based on partially consistent observations', Econometrica 16(1), 1-32.

Nickell, S. (1981), 'Biases in dynamic models with fixed effects', Econometrica 49(6), 14171426.

Robinson, P. M. (2008), 'Developments in the analysis of spatial data', Journal of the Japan Statystical Society 38, 87-96.

Sims, C. (1980), 'Macroeconomics and reality', Econometrica 48, 1-48. 
Table 1: Moran Statistics

\begin{tabular}{lccc}
\hline \hline & $\begin{array}{c}\text { Sharing } \\
\text { Borders }\end{array}$ & $\begin{array}{c}\text { Geographical } \\
\text { Distance }\end{array}$ & $\begin{array}{c}\text { Trade } \\
\text { Distance }\end{array}$ \\
\hline Inflation Equation & 11.02 & 12.68 & 15.08 \\
Output Gap Equation & 8.67 & 9.14 & 11.69 \\
Interest Rate Equation & 10.00 & 12.09 & 13.66 \\
\hline \hline
\end{tabular}

Notes: The Table reports (normalized) Moran statistics calculated across three definitions of the weighting matrix: Sharing Borders, Geographical Distance and Trade Distance. See Section 3.1 for details on these characterizations of the weighting matrix.

Table 2: Model Performance across Weighting Matrices

\begin{tabular}{l|l|c|c}
\hline \hline $\begin{array}{l}\text { Economic } \\
\text { Indicators }\end{array}$ & Weighting & $\begin{array}{c}\text { Spatial Lag } \\
\text { Coefficient }\end{array}$ & Log-lik \\
\hline \multirow{4}{*}{ Inflation } & Sharing Borders & $0.165^{* * *}$ & $\mathbf{- 6 6 0 . 5 8}$ \\
& Geographical Distance & $0.139^{* * *}$ & -671.86 \\
& Trade Distance & $0.169^{* * *}$ & -665.43 \\
\hline \multirow{3}{*}{ Output Gap } & Sharing Borders & $0.210^{* * *}$ & -1051.21 \\
& Geographical Distance & $0.270^{* * *}$ & $\mathbf{- 1 0 4 6 . 0 0}$ \\
& Trade Distance & $0.233^{* * *}$ & $\mathbf{- 1 0 5 6 . 7 7}$ \\
\hline \multirow{3}{*}{ Interest Rate } & Sharing Borders & $0.148^{* * *}$ & -926.41 \\
& Geographical Distance & $0.177^{* * *}$ & $\mathbf{- 9 0 9 . 7 0}$ \\
& Trade Distance & $0.181^{* * *}$ & -921.52 \\
\hline \hline
\end{tabular}

Notes: The Table reports estimated spatial lag coefficients and the value of the log-likelihood across the three definitions of the weighting matrix. $* * *=$ significant at $1 \%$. 
Table 3: Dynamic Spatial Panel Model for Inflation in Europe

$\overline{\pi_{i, t}=\rho_{\pi} \sum_{j=1}^{n} w_{i j} \pi_{j, t}+\phi_{i, \pi \pi} \pi_{i, t-1}+\phi_{i, \pi g} g_{i, t-1}+\phi_{i, \pi r} r_{i, t-1}+\varepsilon_{i, \pi, t}}$

\begin{tabular}{|c|c|c|c|}
\hline \multirow[t]{3}{*}{$\begin{array}{l}\text { Spatial Lag Coeff. }\left(\rho_{\pi}\right) \\
0.139^{* * *} \\
\end{array}$} & \multicolumn{3}{|c|}{$\begin{array}{l}\text { Log-lik. } \\
\quad-671.86 \\
\end{array}$} \\
\hline & \multicolumn{3}{|c|}{ Temporal Auto-Regressive coefficients } \\
\hline & $\pi_{t-1}$ & $y_{t-1}$ & $i_{t-1}$ \\
\hline \multirow[t]{2}{*}{ UK } & $0.767^{* * *}$ & $0.218^{* * *}$ & 0.034 \\
\hline & $(0.045)$ & $(0.059)$ & $(0.032)$ \\
\hline \multirow{2}{*}{ Germany } & $0.726^{* * *}$ & $0.062^{*}$ & 0.076 \\
\hline & $(0.067)$ & $(0.036)$ & $(0.060)$ \\
\hline \multirow[t]{2}{*}{ France } & $0.889^{* * *}$ & -0.007 & -0.028 \\
\hline & $(0.033)$ & $(0.066)$ & $(0.026)$ \\
\hline \multirow[t]{2}{*}{ Italy } & $0.880^{* * *}$ & 0.067 & -0.025 \\
\hline & $(0.030)$ & $(0.053)$ & $(0.022)$ \\
\hline \multirow[t]{2}{*}{ Spain } & $0.819^{* * *}$ & 0.038 & -0.005 \\
\hline & $(0.029)$ & $(0.048)$ & $(0.016)$ \\
\hline \multirow[t]{2}{*}{ Switzerland } & $0.678^{* * *}$ & $0.119^{* * *}$ & $0.083^{*}$ \\
\hline & $(0.059)$ & $(0.058)$ & $(0.043)$ \\
\hline \multirow[t]{2}{*}{ The Netherlands } & $0.844^{* * *}$ & $0.134^{* * *}$ & -0.040 \\
\hline & $(0.045)$ & $(0.051)$ & $(0.028)$ \\
\hline \multirow[t]{2}{*}{ Belgium } & $0.861^{* * *}$ & -0.015 & -0.010 \\
\hline & $(0.041)$ & $(0.034)$ & $(0.023)$ \\
\hline \multirow[t]{2}{*}{ Portugal } & $0.941^{* * *}$ & $0.115^{* * *}$ & -0.013 \\
\hline & $(0.018)$ & $(0.036)$ & $(0.016)$ \\
\hline \multirow[t]{2}{*}{ Austria } & $0.691^{* * *}$ & $0.143^{* * *}$ & 0.026 \\
\hline & $(0.058)$ & $(0.066)$ & $(0.049)$ \\
\hline \multirow[t]{2}{*}{ Denmark } & $0.910^{* * *}$ & $0.119^{* * *}$ & -0.025 \\
\hline & $(0.031)$ & $(0.043)$ & $(0.028)$ \\
\hline
\end{tabular}

Notes: The Table shows estimation results of the dynamic spatial panel data model for inflation in eleven European countries using the weighting matrix based on the geographical distance and data over the period 1981: $1-2008: 4 .{ }^{* * *}=$ significant at $1 \% ;{ }^{* *}=$ significant at $5 \%$; and ${ }^{*}=$ significant at $10 \%$. The critical values for $1 \%, 5 \%$ and $10 \%$ significance levels are: $2.58 ; 1.96$; and 1.64 respectively. 
Table 4: Dynamic Spatial Panel Model for Output gap in Europe

$\overline{g_{i, t}=\rho_{g} \sum_{j=1}^{n} w_{i j} g_{j, t}+\phi_{i, g \pi} \pi_{i, t-1}+\phi_{i, g g} g_{i, t-1}+\phi_{i, g r} r_{i, t-1}+\varepsilon_{i, g, t}}$

\begin{tabular}{cc}
\hline Spatial Lag Coeff. $\left(\rho_{g}\right)$ & Log-lik. \\
$0.27^{* * *}$ & -1046.00 \\
\hline
\end{tabular}

UK

Temporal Auto-Regressive coefficients

\begin{tabular}{|c|c|c|c|}
\hline & \\
\hline & $\pi_{t-1}$ & $y_{t-1}$ & $i_{t-1}$ \\
\hline \multirow[t]{2}{*}{ UK } & $-0.110^{*}$ & $0.738^{* * *}$ & 0.046 \\
\hline & $(0.058)$ & $(0.081)$ & $(0.043)$ \\
\hline \multirow[t]{2}{*}{ Germany } & 0.040 & $0.725^{* * *}$ & 0.019 \\
\hline & $(0.089)$ & $(0.048)$ & $(0.081)$ \\
\hline \multirow[t]{2}{*}{ France } & 0.013 & $0.704^{* * *}$ & 0.003 \\
\hline & $(0.044)$ & $(0.091)$ & $(0.035)$ \\
\hline \multirow[t]{2}{*}{ Italy } & -0.025 & $0.679^{* * *}$ & 0.009 \\
\hline & $(0.039)$ & $(0.073)$ & 0.029 \\
\hline \multirow[t]{2}{*}{ Spain } & -0.045 & $0.614^{* * *}$ & 0.022 \\
\hline & $(0.035)$ & $(0.066)$ & $(0.021)$ \\
\hline \multirow[t]{2}{*}{ Switzerland } & $-0.127^{*}$ & $0.761^{* * *}$ & 0.061 \\
\hline & $(0.076)$ & $(0.079)$ & $(0.058)$ \\
\hline \multirow[t]{2}{*}{ The Netherlands } & -0.074 & $0.656^{* * *}$ & -0.007 \\
\hline & $(0.059)$ & $(0.069)$ & $(0.037)$ \\
\hline \multirow[t]{2}{*}{ Belgium } & 0.063 & $0.559^{* * *}$ & -0.023 \\
\hline & $(0.054)$ & $(0.046)$ & $(0.031)$ \\
\hline \multirow[t]{2}{*}{ Portugal } & -0.001 & $0.656^{* * *}$ & -0.005 \\
\hline & $(0.023)$ & $(0.049)$ & $(0.021)$ \\
\hline \multirow[t]{2}{*}{ Austria } & -0.051 & $0.451^{* * *}$ & 0.066 \\
\hline & $(0.075)$ & $(0.090)$ & $(0.067)$ \\
\hline \multirow[t]{2}{*}{ Denmark } & -0.007 & $0.549^{* * *}$ & -0.054 \\
\hline & $(0.041)$ & $(0.059)$ & $(0.037)$ \\
\hline
\end{tabular}

Notes: The Table shows estimation results of the dynamic spatial panel data model for the output gap in eleven European countries using the weighting matrix based on the geographical distance and data over the period 1981 : $1-2008: 4{ }^{* * *}=$ significant at $1 \% ;{ }^{* *}=$ significant at $5 \%$; and ${ }^{*}=$ significant at $10 \%$. The critical values for $1 \%$, $5 \%$ and $10 \%$ significance levels are: $2.58 ; 1.96$; and 1.64 respectively. 
Table 5: Dynamic Spatial Panel Model for Interest Rate in Europe $\overline{r_{i, t}=\rho_{r} \sum_{j=1}^{n} w_{i j} r_{j, t}+\phi_{i, r \pi} \pi_{i, t-1}+\phi_{i, r g} g_{i, t-1}+\phi_{i, r r} r_{i, t-1}+\varepsilon_{i, r, t}}$

\begin{tabular}{|c|c|c|c|}
\hline \multirow[t]{3}{*}{$\begin{array}{l}\text { Spatial Lag Coeff. }\left(\rho_{r}\right) \\
0.177^{* * *}\end{array}$} & \multicolumn{3}{|c|}{$\begin{array}{r}\text { Log-lik. } \\
-909.70 \\
\end{array}$} \\
\hline & \multicolumn{3}{|c|}{ Temporal Auto-Regressive coefficients } \\
\hline & $\pi_{t-1}$ & $y_{t-1}$ & $i_{t-1}$ \\
\hline \multirow[t]{2}{*}{ UK } & -0.035 & $0.364^{* * *}$ & $0.804^{* * *}$ \\
\hline & $(0.052)$ & $(0.074)$ & $(0.042)$ \\
\hline \multirow[t]{2}{*}{ Germany } & 0.037 & $0.0756^{*}$ & $0.698^{* * *}$ \\
\hline & $(0.080)$ & $(0.043)$ & $(0.076)$ \\
\hline \multirow[t]{2}{*}{ France } & $0.013^{* * *}$ & 0.117 & $0.738^{* * *}$ \\
\hline & $(0.040)$ & $(0.080)$ & $(0.035)$ \\
\hline \multirow[t]{2}{*}{ Italy } & $0.097^{* * *}$ & $0.186^{* * *}$ & $0.797^{* * *}$ \\
\hline & $(0.035)$ & $(0.065)$ & $(0.030)$ \\
\hline \multirow[t]{2}{*}{ Spain } & 0.137 & 0.072 & $0.764^{* * *}$ \\
\hline & $(0.032)$ & $(0.058)$ & $(0.021)$ \\
\hline \multirow[t]{2}{*}{ Switzerland } & -0.096 & $0.232^{* * *}$ & $0.767^{* * *}$ \\
\hline & $(0.069)$ & $(0.072)$ & $(0.055)$ \\
\hline \multirow[t]{2}{*}{ The Netherlands } & -0.023 & $0.174^{* * *}$ & $0.786^{* * *}$ \\
\hline & $(0.054)$ & $(0.061)$ & $(0.037)$ \\
\hline \multirow[t]{2}{*}{ Belgium } & 0.017 & 0.002 & $0.848^{* * *}$ \\
\hline & $(0.049)$ & $(0.042)$ & $(0.031)$ \\
\hline \multirow[t]{2}{*}{ Portugal } & $0.084^{* * *}$ & $0.133^{* * *}$ & $0.825^{* * *}$ \\
\hline & $(0.021)$ & $(0.044)$ & $(0.021)$ \\
\hline \multirow[t]{2}{*}{ Austria } & $-0.133^{* *}$ & $0.187^{* * *}$ & $0.755^{* * *}$ \\
\hline & $(0.068)$ & $(0.080)$ & $(0.063)$ \\
\hline \multirow[t]{2}{*}{ Denmark } & 0.026 & $0.089^{*}$ & $0.842^{* * *}$ \\
\hline & $(0.037)$ & $(0.052)$ & $(0.035)$ \\
\hline
\end{tabular}

Notes: The Table shows estimation results of the dynamic spatial panel data model for the interest rate in eleven European countries using the weighting matrix based on the geographical distance and data over the period 1981:1-2008:4. ${ }^{* *}=$ significant at $1 \%$; ${ }^{* *}=$ significant at $5 \%$; and ${ }^{*}=$ significant at $10 \%$. The critical values for $1 \%, 5 \%$ and $10 \%$ significance levels are: $2.58 ; 1.96$; and 1.64 respectively. 
Table 6: Variance Decomposition for inflation: 5 Year horizon, Country AGGREGATES

\begin{tabular}{l|ccccccccccc}
\hline \hline & \multicolumn{10}{c}{ Shocks originating from country } \\
\cline { 2 - 11 } & UK & GER & FR & IT & SP & SE & NET & BEL & POR & AUT & DEN \\
\hline UK & 0.421 & 0.109 & 0.305 & 0.022 & 0.078 & 0.023 & 0.011 & 0.004 & 0.020 & 0.002 & 0.005 \\
GER & 0.124 & 0.575 & 0.128 & 0.015 & 0.039 & 0.039 & 0.039 & 0.003 & 0.002 & 0.016 & 0.020 \\
FR & 0.128 & 0.185 & 0.598 & 0.015 & 0.039 & 0.011 & 0.009 & 0.008 & 0.004 & 0.000 & 0.002 \\
IT & 0.057 & 0.140 & 0.251 & 0.344 & 0.116 & 0.027 & 0.012 & 0.005 & 0.044 & 0.002 & 0.001 \\
SP & 0.074 & 0.099 & 0.320 & 0.077 & 0.372 & 0.017 & 0.006 & 0.003 & 0.032 & 0.000 & 0.001 \\
SE & 0.127 & 0.256 & 0.179 & 0.047 & 0.053 & 0.317 & 0.004 & 0.005 & 0.007 & 0.004 & 0.000 \\
NET & 0.114 & 0.195 & 0.093 & 0.025 & 0.024 & 0.019 & 0.463 & 0.005 & 0.003 & 0.006 & 0.054 \\
BEL & 0.085 & 0.270 & 0.216 & 0.015 & 0.015 & 0.036 & 0.034 & 0.322 & 0.002 & 0.001 & 0.004 \\
POR & 0.064 & 0.073 & 0.471 & 0.021 & 0.162 & 0.035 & 0.018 & 0.009 & 0.146 & 0.001 & 0.000 \\
AUT & 0.083 & 0.187 & 0.131 & 0.033 & 0.067 & 0.049 & 0.076 & 0.020 & 0.004 & 0.338 & 0.010 \\
DEN & 0.086 & 0.143 & 0.095 & 0.069 & 0.037 & 0.010 & 0.067 & 0.002 & 0.004 & 0.032 & 0.455 \\
& & & & & & & & & & & \\
\hline \hline
\end{tabular}

Notes: The table shows the variance decomposition of the inflation dynamics over a five year horizon. The shocks are aggregated over the countries. Entries, thus, give the fraction of total variance of inflation per country (row) explained by shocks originating in each of the countries (columns). 
Table 7: Variance Decomposition for output gap: 5 Year horizon, Country AGGREGATES

\begin{tabular}{l|cccccccccccc}
\hline \hline & \multicolumn{10}{c}{ Shocks originating from country } \\
\cline { 2 - 11 } & UK & GER & FR & IT & SP & SE & NET & BEL & POR & AUT & DEN \\
\hline \multirow{2}{*}{ UK } & 0.611 & 0.051 & 0.199 & 0.021 & 0.035 & 0.021 & 0.028 & 0.010 & 0.011 & 0.006 & 0.007 \\
GER & 0.087 & 0.471 & 0.107 & 0.021 & 0.042 & 0.046 & 0.063 & 0.109 & 0.016 & 0.031 & 0.008 \\
FR & 0.149 & 0.121 & 0.592 & 0.023 & 0.054 & 0.036 & 0.006 & 0.012 & 0.005 & 0.001 & 0.001 \\
IT & 0.137 & 0.042 & 0.285 & 0.375 & 0.045 & 0.037 & 0.017 & 0.033 & 0.013 & 0.013 & 0.002 \\
SP & 0.121 & 0.055 & 0.386 & 0.037 & 0.316 & 0.026 & 0.012 & 0.008 & 0.014 & 0.022 & 0.002 \\
SE & 0.174 & 0.085 & 0.156 & 0.035 & 0.031 & 0.479 & 0.009 & 0.021 & 0.005 & 0.004 & 0.001 \\
NET & 0.063 & 0.047 & 0.171 & 0.026 & 0.047 & 0.124 & 0.414 & 0.039 & 0.002 & 0.004 & 0.064 \\
BEL & 0.065 & 0.104 & 0.170 & 0.205 & 0.064 & 0.055 & 0.023 & 0.275 & 0.004 & 0.006 & 0.028 \\
POR & 0.081 & 0.015 & 0.434 & 0.046 & 0.110 & 0.014 & 0.010 & 0.023 & 0.242 & 0.020 & 0.004 \\
AUT & 0.077 & 0.103 & 0.127 & 0.020 & 0.026 & 0.153 & 0.018 & 0.018 & 0.003 & 0.418 & 0.037 \\
DEN & 0.203 & 0.044 & 0.170 & 0.033 & 0.042 & 0.047 & 0.053 & 0.009 & 0.014 & 0.109 & 0.277 \\
& & & & & & & & & & & \\
\hline \hline
\end{tabular}

Notes: The table shows the variance decomposition of the output gap dynamics over a five year horizon. The shocks are aggregated over the countries. Entries, thus, give the fraction of total variance of output gap per country (row) explained by shocks originating in each of the countries (columns). 
Table 8: VARIANCE DECOMPOSITION FOR THE SHORT-TERM INTEREst RATE: 5 yeAR HORIZON, COUNTRY AGGREGATES

\begin{tabular}{l|ccccccccccc}
\hline \hline & \multicolumn{10}{|c}{ Shocks originating from country } \\
\hline & UK & GER & FR & IT & SP & SE & NET & BEL & POR & AUT & DEN \\
\hline UK & 0.415 & 0.100 & 0.291 & 0.017 & 0.063 & 0.029 & 0.042 & 0.017 & 0.020 & 0.003 & 0.003 \\
GER & 0.144 & 0.441 & 0.194 & 0.023 & 0.052 & 0.063 & 0.035 & 0.023 & 0.004 & 0.014 & 0.008 \\
FR & 0.168 & 0.196 & 0.487 & 0.017 & 0.059 & 0.031 & 0.020 & 0.005 & 0.014 & 0.002 & 0.001 \\
IT & 0.161 & 0.124 & 0.378 & 0.144 & 0.084 & 0.030 & 0.019 & 0.013 & 0.033 & 0.009 & 0.004 \\
SP & 0.149 & 0.092 & 0.449 & 0.026 & 0.134 & 0.030 & 0.030 & 0.006 & 0.043 & 0.007 & 0.033 \\
SE & 0.172 & 0.206 & 0.222 & 0.022 & 0.048 & 0.272 & 0.022 & 0.015 & 0.011 & 0.006 & 0.003 \\
NET & 0.189 & 0.209 & 0.208 & 0.014 & 0.052 & 0.053 & 0.209 & 0.038 & 0.007 & 0.006 & 0.015 \\
BEL & 0.187 & 0.189 & 0.274 & 0.033 & 0.060 & 0.050 & 0.036 & 0.147 & 0.009 & 0.012 & 0.002 \\
POR & 0.155 & 0.081 & 0.452 & 0.030 & 0.105 & 0.025 & 0.021 & 0.023 & 0.101 & 0.003 & 0.005 \\
AUT & 0.132 & 0.279 & 0.194 & 0.032 & 0.033 & 0.065 & 0.026 & 0.021 & 0.008 & 0.197 & 0.011 \\
DEN & 0.210 & 0.217 & 0.211 & 0.027 & 0.048 & 0.033 & 0.039 & 0.023 & 0.007 & 0.029 & 0.156 \\
& & & & & & & & & & & \\
\hline \hline
\end{tabular}

Notes: The table shows the variance decomposition of the interest rate dynamics over a five year horizon. The shocks are aggregated over the countries. Entries, thus, give the fraction of total variance of interest rate per country (row) explained by shocks originating in each of the countries (columns). 


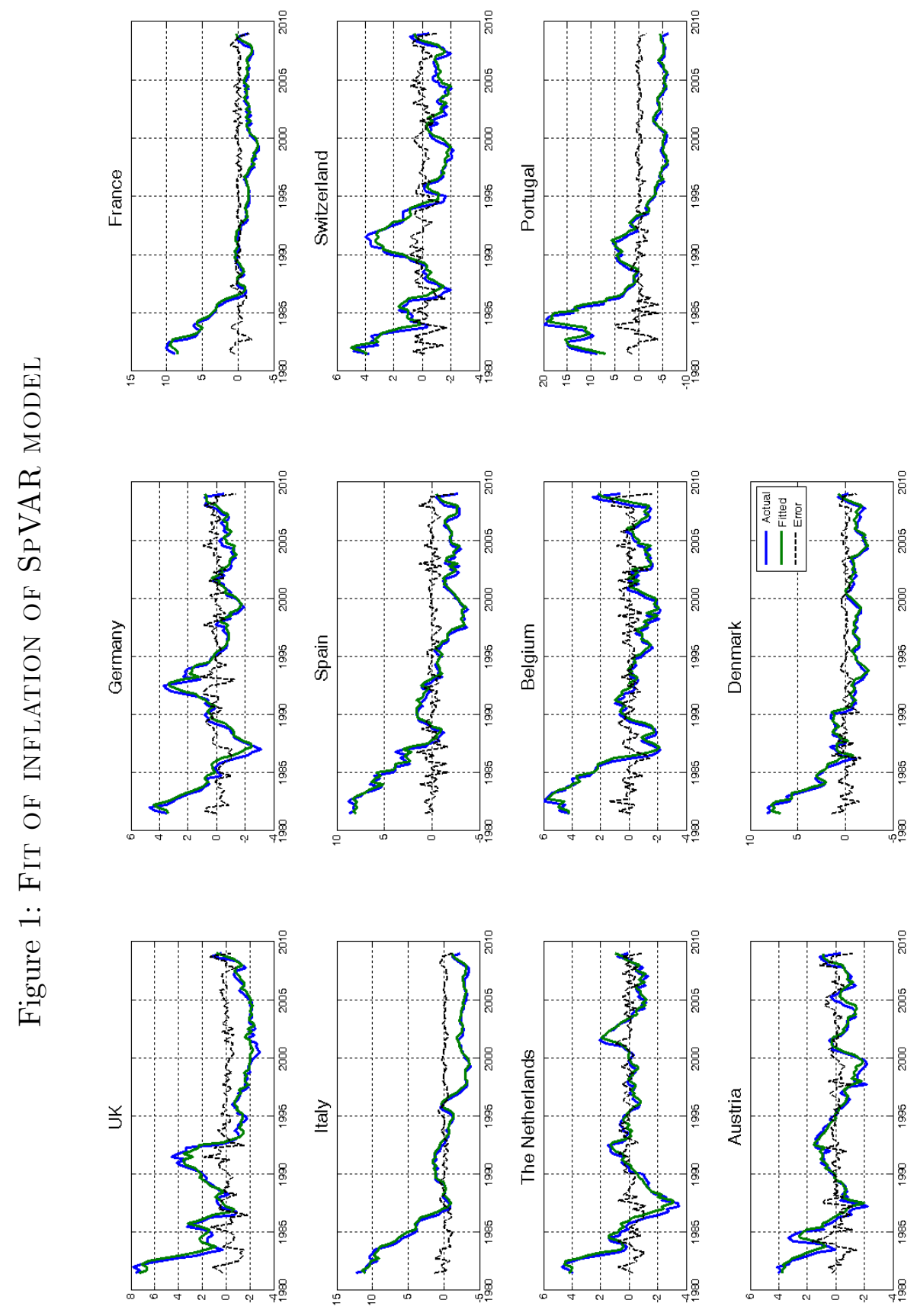




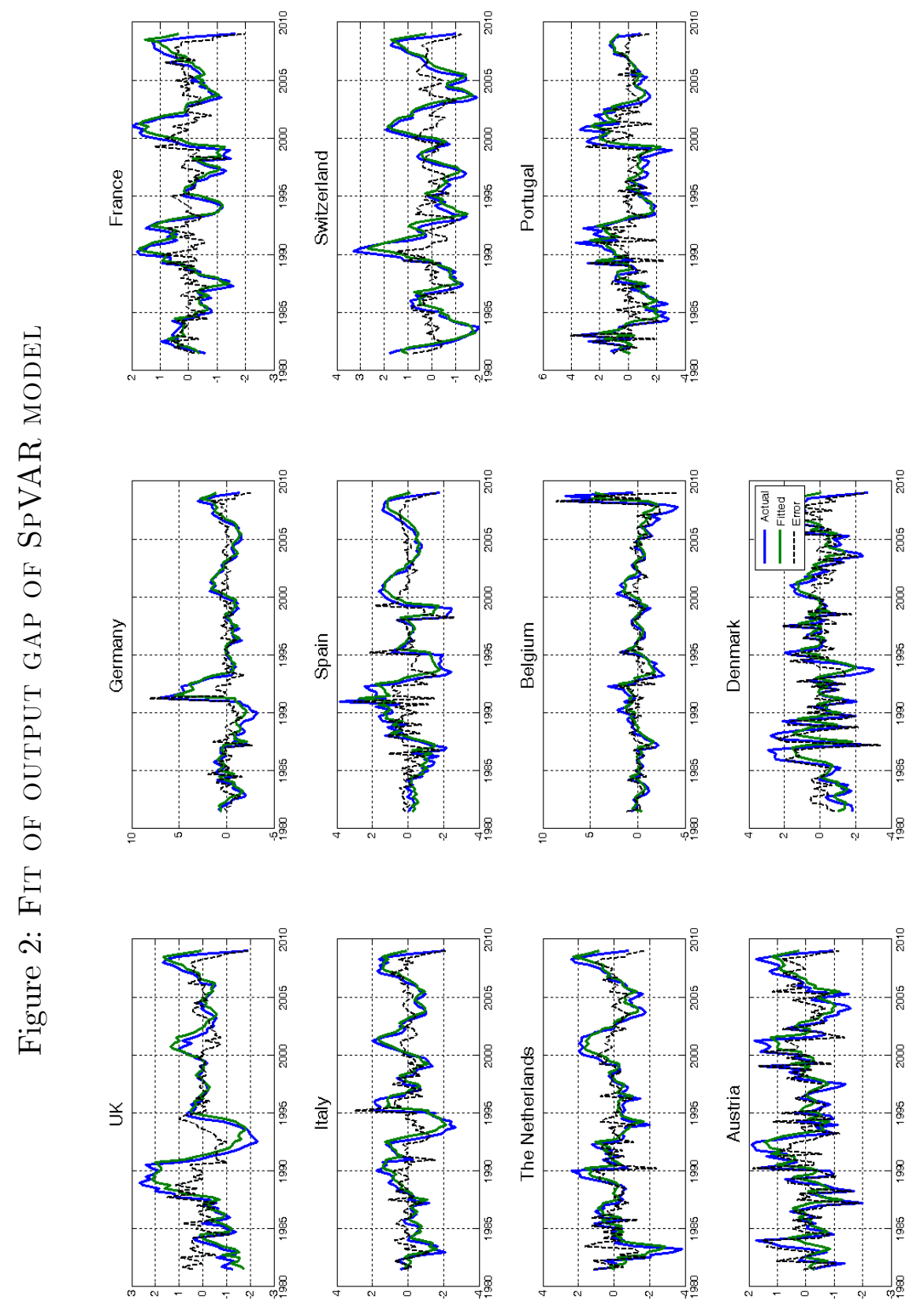




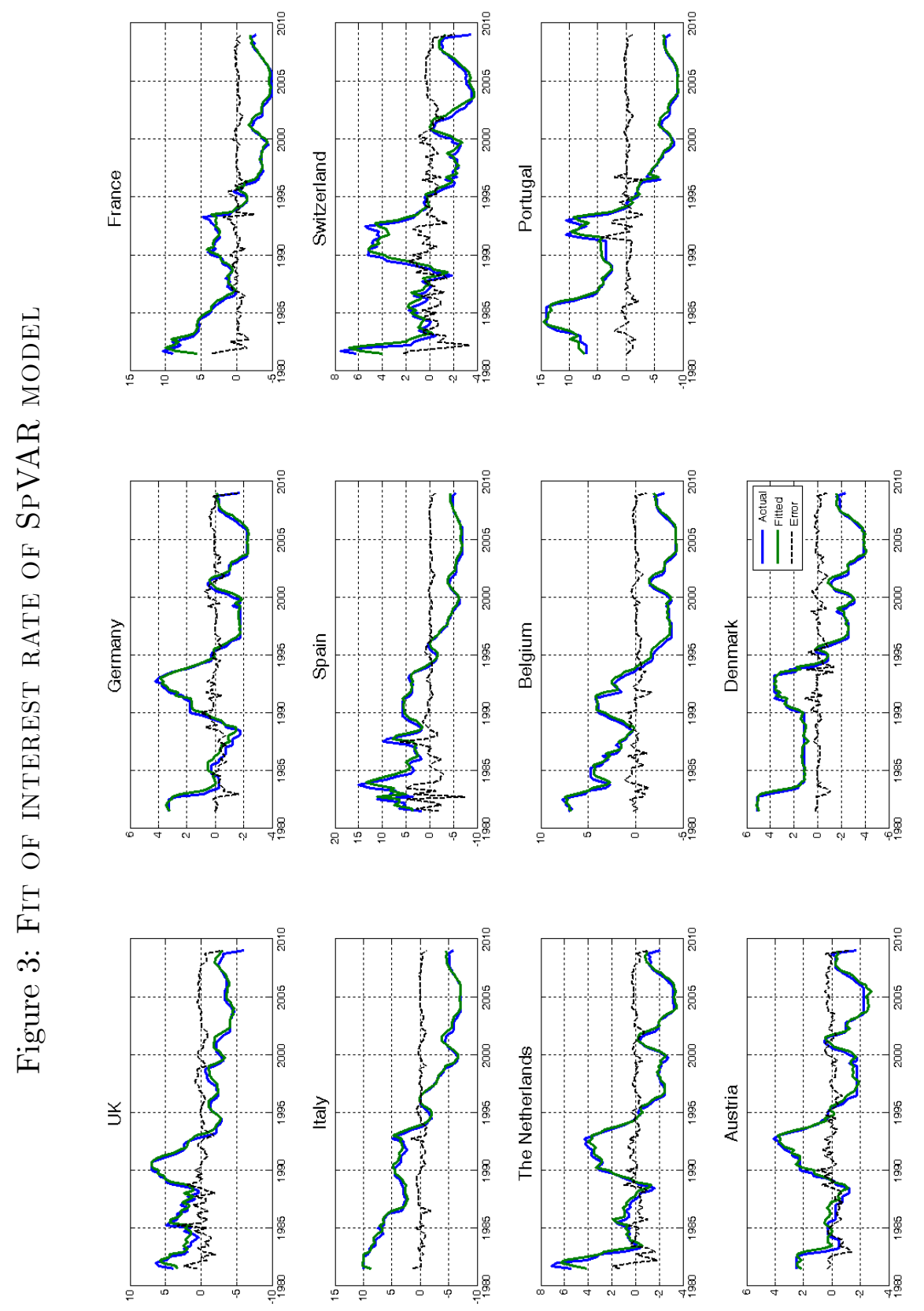



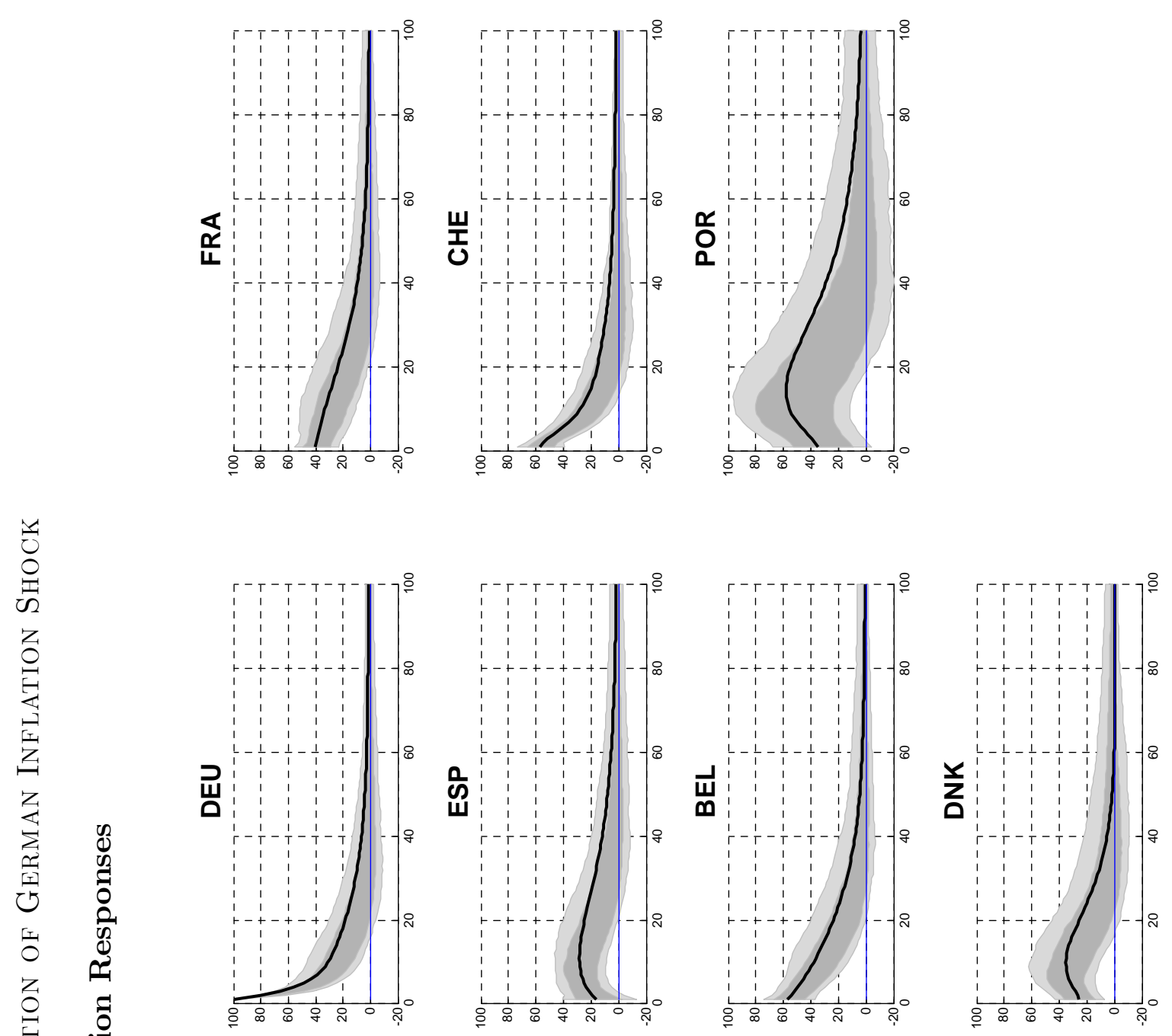

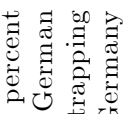
84 范 ㄱ. 鹪. 击 0 兽焉.

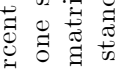
¿ $\approx$. $\infty$ 요뭉

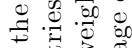
考苛焉 矛芯芯

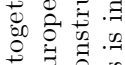
可牙话 寻苋过 그ㅇㅝㅠ

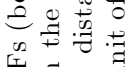

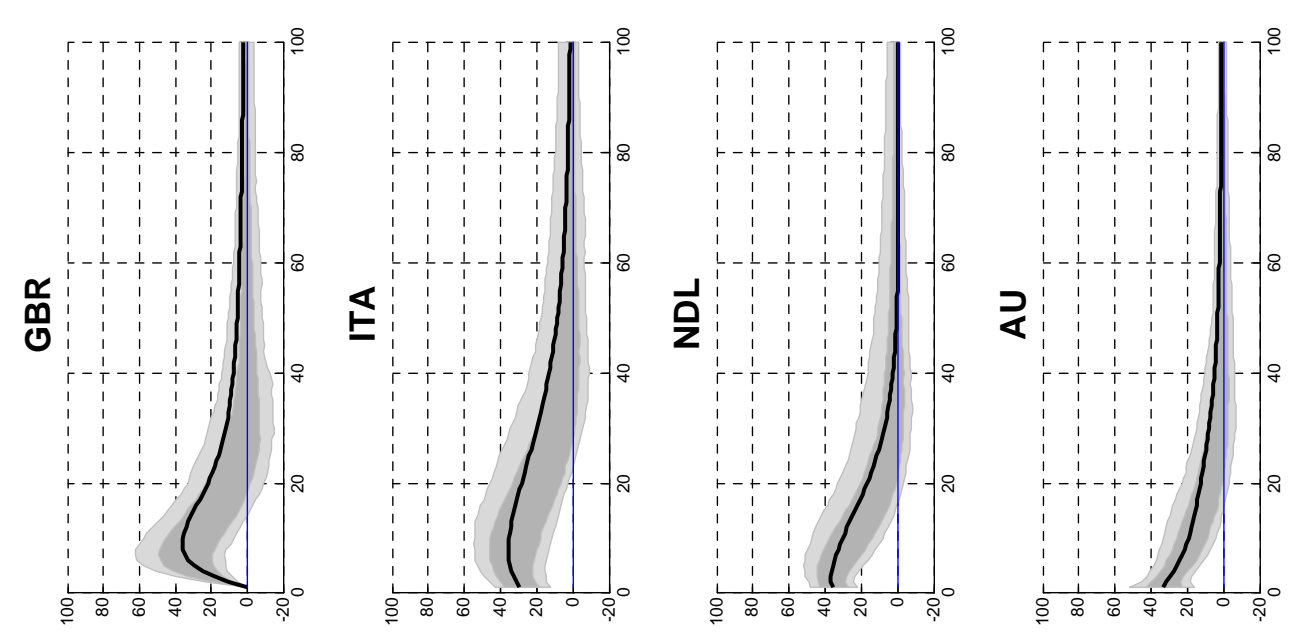

出.

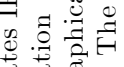

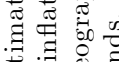

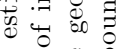

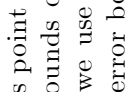
$\begin{array}{lll}1 & 0 \\ 0 & 0 & 0 \\ 0 & 0 & 0\end{array}$

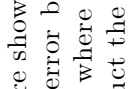

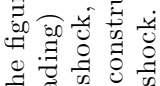
$\forall \frac{\pi}{\omega}$ 表요

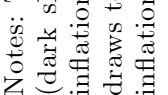



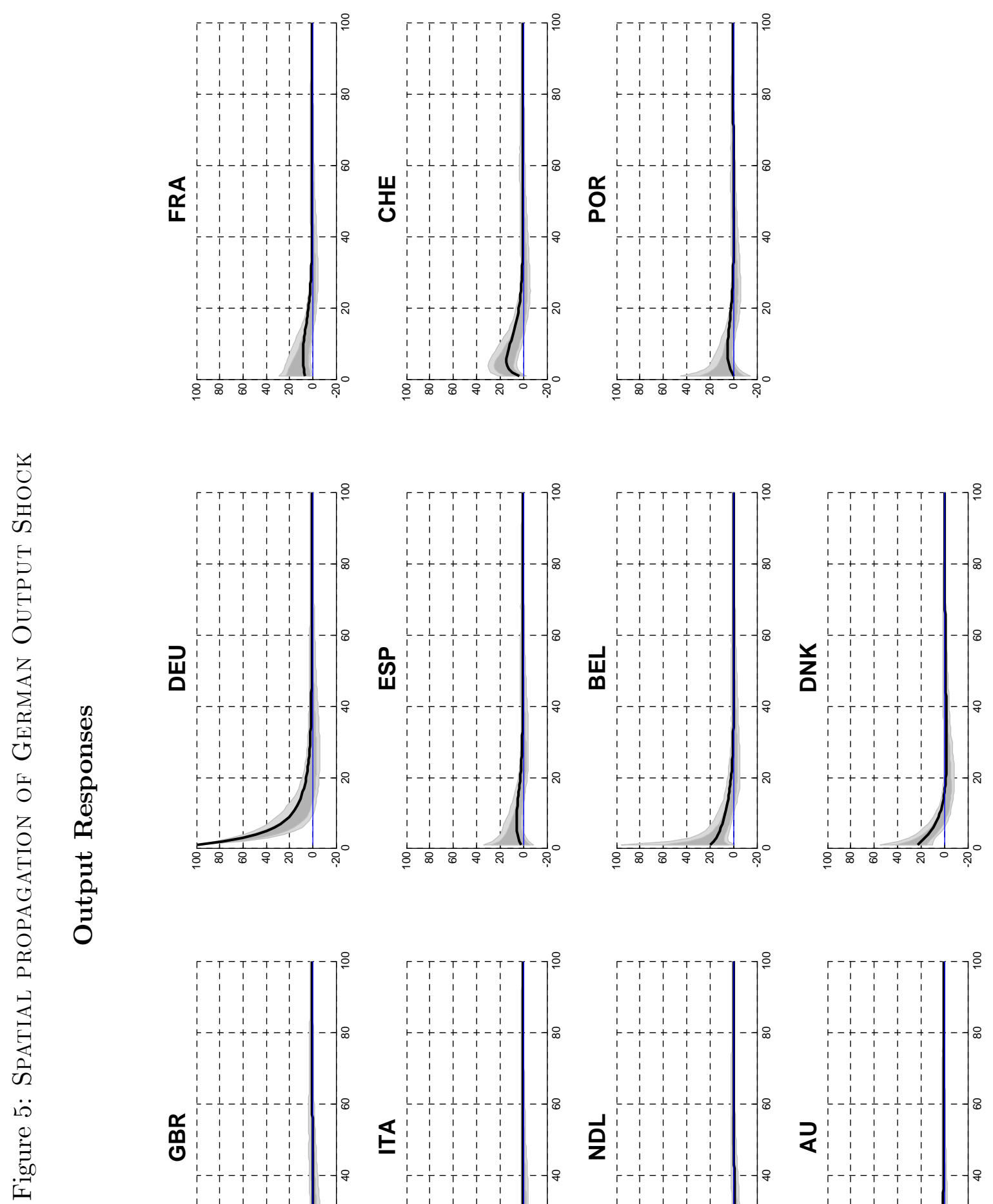

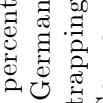

\&ั4

경

की.

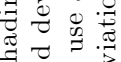

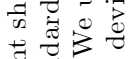

兽焉.

氙苛焉

范 0.0

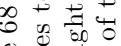

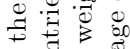

青吉导焉

ฮี

馬

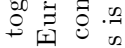

की

웜

过范

舟. 苛
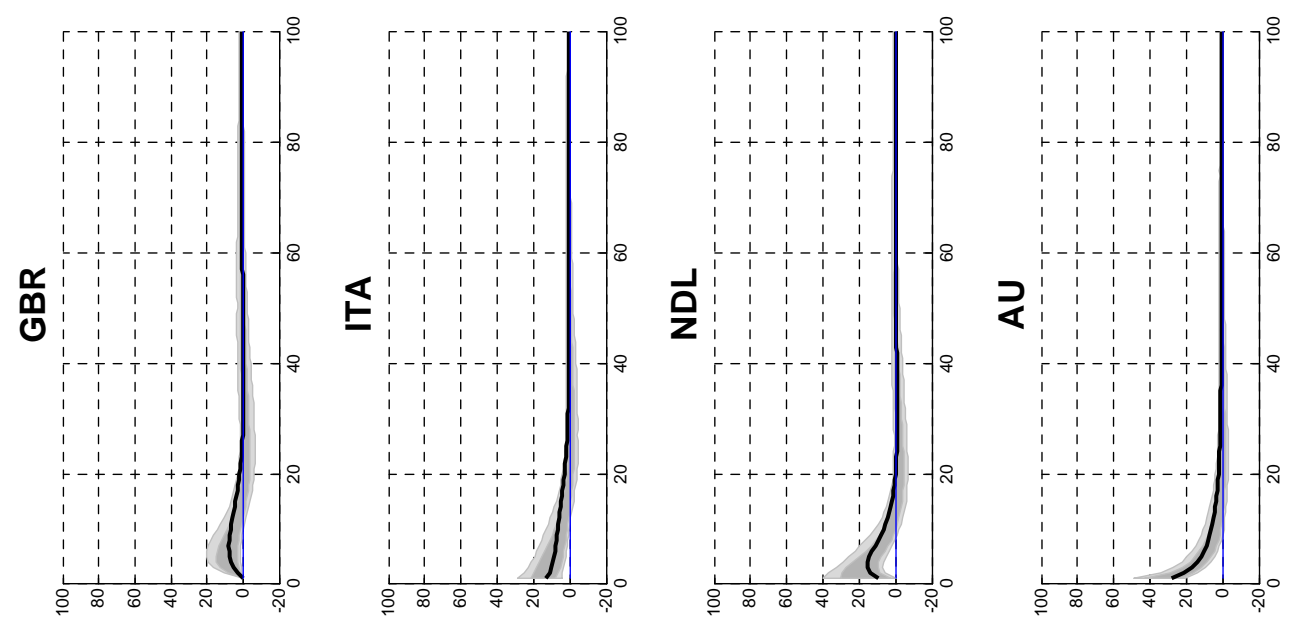

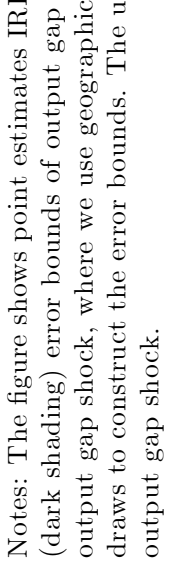




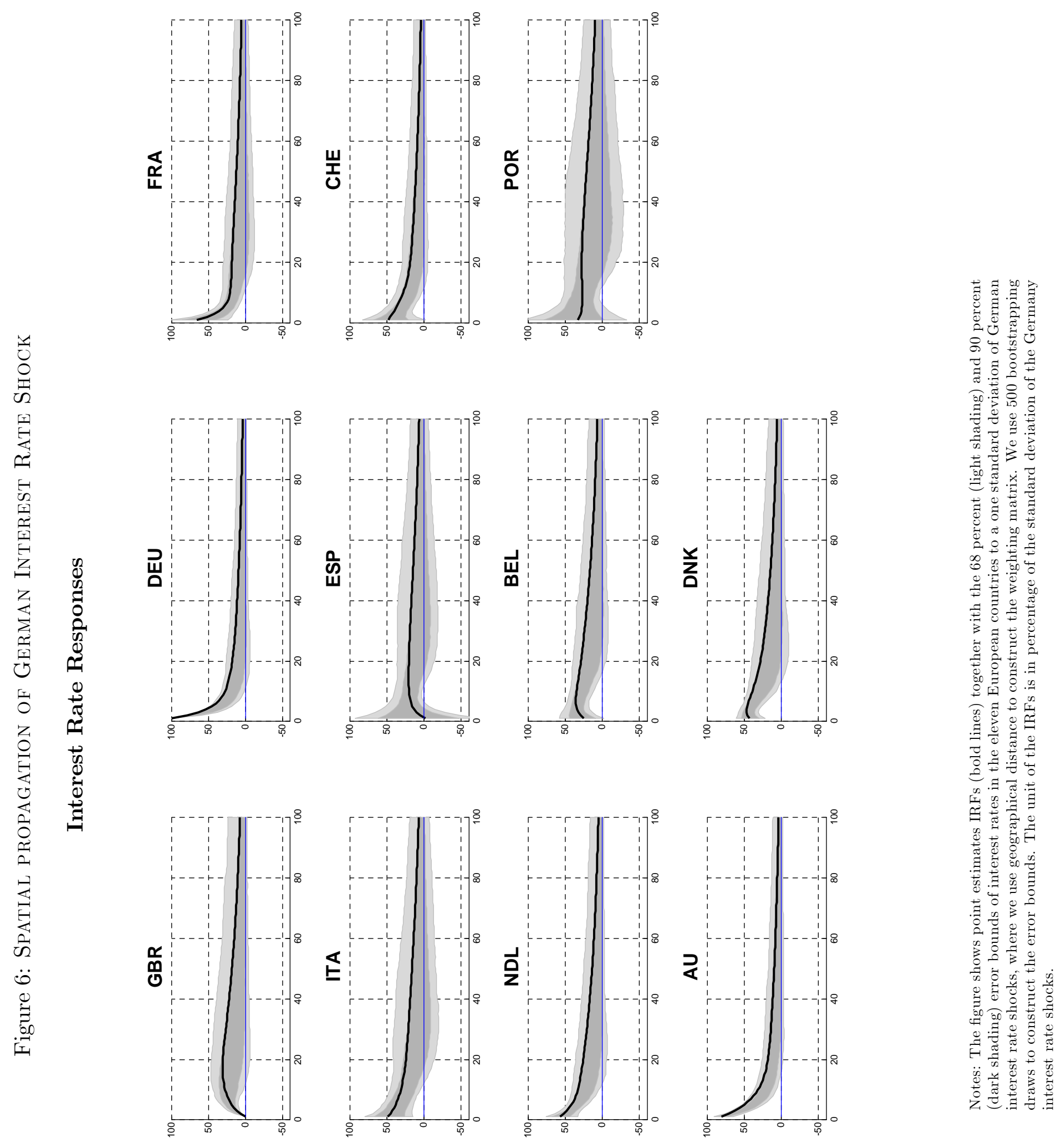



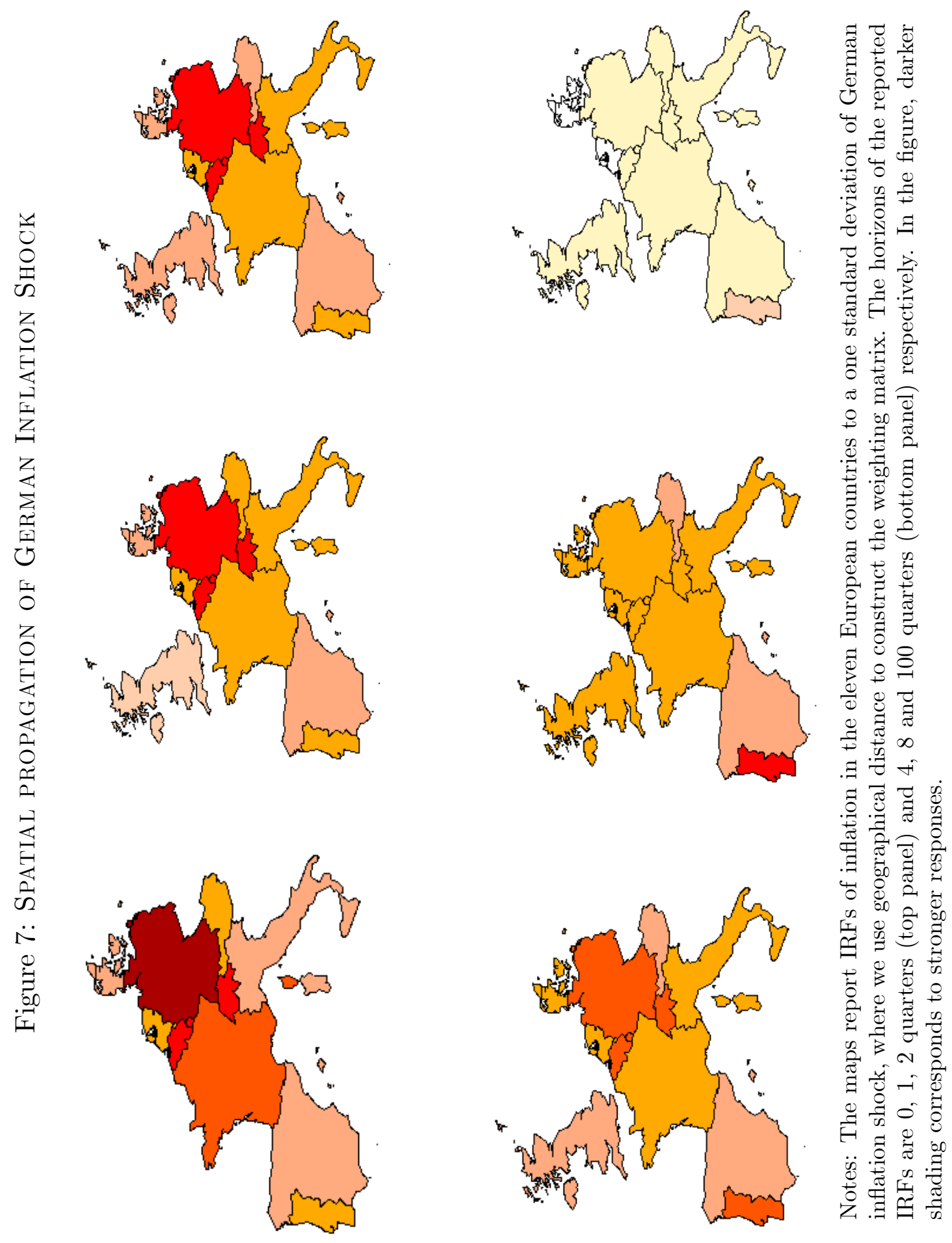

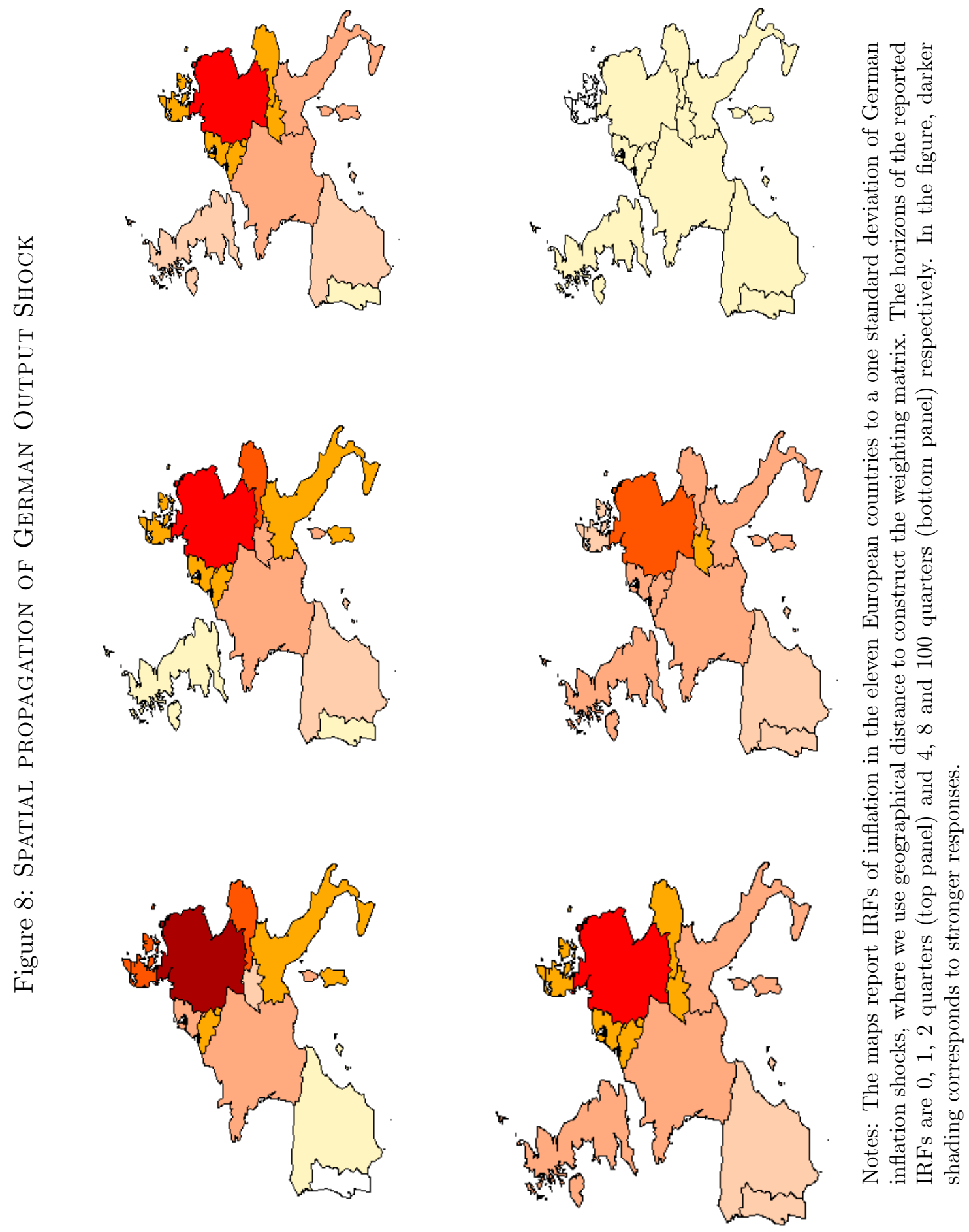

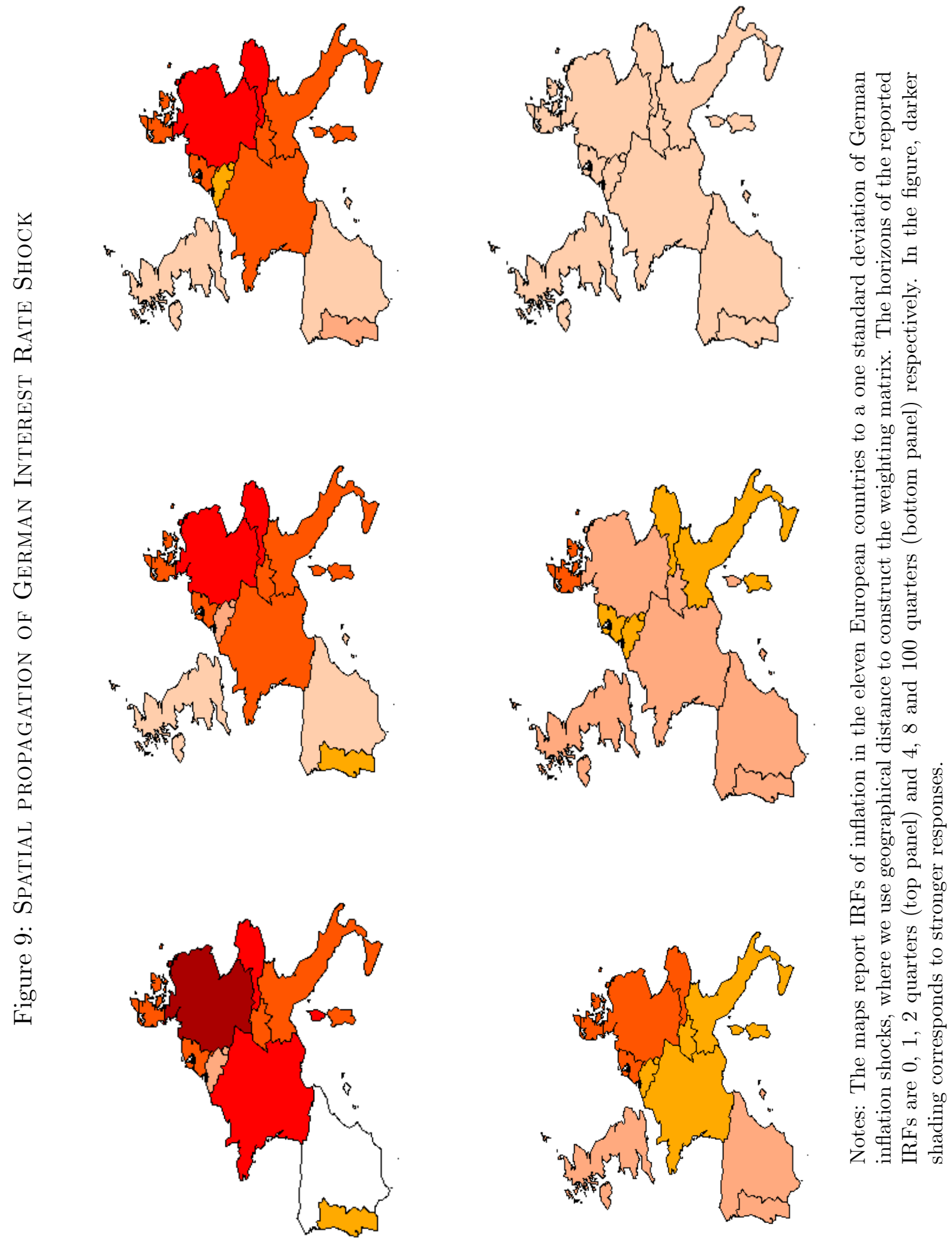
Copyright ( 2010 @ the author(s). Discussion papers are in draft form. This discussion paper is distributed for purposes of comment and discussion only. It may not be reproduced without permission of the copyright holder. Copies of working papers are available from the author. 